\title{
RIMER and SA based Thermal Efficiency Optimization for Fired
}

\section{Heaters}

\author{
Xiaoyong Gao a, b, Lugang Qi ${ }^{\text {a, c }}$, Wenxiang Lyu ${ }^{\text {a }}$, Tao Chen ${ }^{\text {d }}$, Dexian Huang ${ }^{\text {a,* }}$

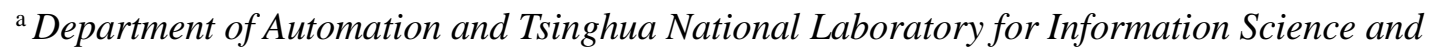 \\ Technology, Tsinghua University, Beijing 100084, China \\ ${ }^{\mathrm{b}}$ Institute for Ocean Engineering, China University of Petroleum, Beijing, 102249, China \\ ${ }^{\mathrm{c}}$ Department of Information and Automation, Hesteel Tangsteel Group, Tangshan, 063000, China \\ ${ }^{\mathrm{d}}$ Department of Chemical and Process Engineering, University of Surrey, Guildford, GU2 7XH, UK
}

\begin{abstract}
Due to frequent changes in thermal load and drift of online oxygen analyzer, the heater's thermal efficiency optimization system with limited maintenance resources seldom works in long term. To solve this problem, a novel and practical optimization method combing RIMER (i.e. belief rule-base inference methodology using the evidential reasoning) approach and SA (stochastic approximation) online self-optimization is proposed. The optimization scheme consists of (i) an off-line expert system that determines the optimal steady state operation for a given thermal load, and (ii) an on-line optimization system that further improves the thermal efficiency to alleviate the influence caused by sensors' drift. In more details, at the off-line stage, a belief-rule-base (BRB) expert system is constructed to determine good initial references of operating conditions for a specified thermal load, which quickly drives the system to a near optimal operation point when confronted with the thermal load change; this is based on RIMER. During on-line operation, these off-line determined initial values are further refined by using
\end{abstract}

\footnotetext{
${ }^{*}$ Corresponding author. Tel.: +86-10-62784964; fax: +86-10-62786911.

E-mail address: huangdx@tsinghua.edu.cn
} 
the SA approach to optimize the thermal efficiency. The newly obtained optimal operating condition then is updated online to compensate the sensor's drift. The optimized profile is implemented through a practical control strategy for the flue gas - air system of fired heaters, which is applied to the flue gas oxygen concentration and chamber negative pressure control on the basis of flue gas-air control system. Simulation results on the UniSim ${ }^{\mathrm{TM}}$ Design platform demonstrate the feasibility of the proposed optimization scheme. Furthermore, the field implementation results at a real process illustrate the effectiveness of this optimization system. Both simulation and field application show that the thermal efficiency can be nearly improved by c. $1 \%$.

Key words: Fired heaters, Thermal efficiency optimization, RIMER, Flue gas - air control system 


\begin{tabular}{|c|c|}
\hline \multicolumn{2}{|l|}{ Nomenclature } \\
\hline$\eta$ & thermal efficiency $(\%)$ \\
\hline$\xi$ & excess air ratio \\
\hline$Q_{e}$ & efficient thermal load $(\mathrm{kJ} / \mathrm{h})$ \\
\hline$Q_{f}$ & total heat provided by fuel combustion $(\mathrm{kJ} / \mathrm{h})$ \\
\hline$Q_{i c}, Q_{f g}, Q_{l o s s}$ & heat losses of incomplete combustion, flue gas, dissipation $(\mathrm{kJ} / \mathrm{h})$ \\
\hline$\theta_{k}, \omega_{k}$ & the original and activation weight of the $k$ th rule \\
\hline \multirow[t]{2}{*}{$\alpha_{k}$} & the matching degree to which subregion the input matches in the \\
\hline & $k$ th rule \\
\hline \multirow[t]{2}{*}{$\beta_{j k}, \beta_{j}$} & the original belief degree assessed to $D_{j}$ in the $k$ th rule, and \\
\hline & combined belief degree assessed to $D_{j}$ \\
\hline $\mathrm{O}_{2}$ & oxygen concentration $(\%)$ of flue gas \\
\hline$P$ & negative pressure of the combustion chamber $(\mathrm{Pa})$ \\
\hline \multicolumn{2}{|l|}{ Subscripts } \\
\hline$f$ & fuel \\
\hline$a$ & air \\
\hline$f d$ & feed \\
\hline$f g$ & flue gas \\
\hline
\end{tabular}

\section{Introduction}

Fired heaters, which are widely used especially in the petrochemical industry to heat hydrocarbons, hot oil, steam and air, are probably the largest energy consumer in a typical petrochemical plant, accounting for as much as $75 \%$ of the fuel used $[1,2]$. As such, even small improvement in thermal 
efficiency can substantially save the operation cost and reduce the impact on environment [3]. Therefore, improving thermal efficiency has received significant interest in both academic research and industrial practice.

To this end, one useful approach is to revamp the inefficient, undersized or even unsafe heaters through modified designs and equipment retrofitting. Over the past 20 years, substantial effort has been invested along this direction, with a large number of successful applications reported [1-5]. Typically, retrofitting involves a combination of the following options [1]:

- The physical design of a fired heater is modified to increase throughput and conserve energy.

- Cleaner and/or alternative fuels, and air preheating are employed to improve energy efficiency.

- Equipment is repaired or replaced.

- Control instrumentation is added/updated to reduce operation variability.

- Maintenance strategies and methods are improved.

In addition, Mussati et al. integrated these design options into a mathematical optimization problem, which was solved by using mixed integer nonlinear programming [6]. Nevertheless, these approaches rely on process knowledge and experience of the designers, thus the level of success strongly depends on the know-how $[2,5]$. Retrofitting is also capital intensive, which is a major barrier to its uptake in practice. Furthermore, optimally (re-)designed heaters also need optimal on-line operation to maximize their potential in improving thermal efficiency. 


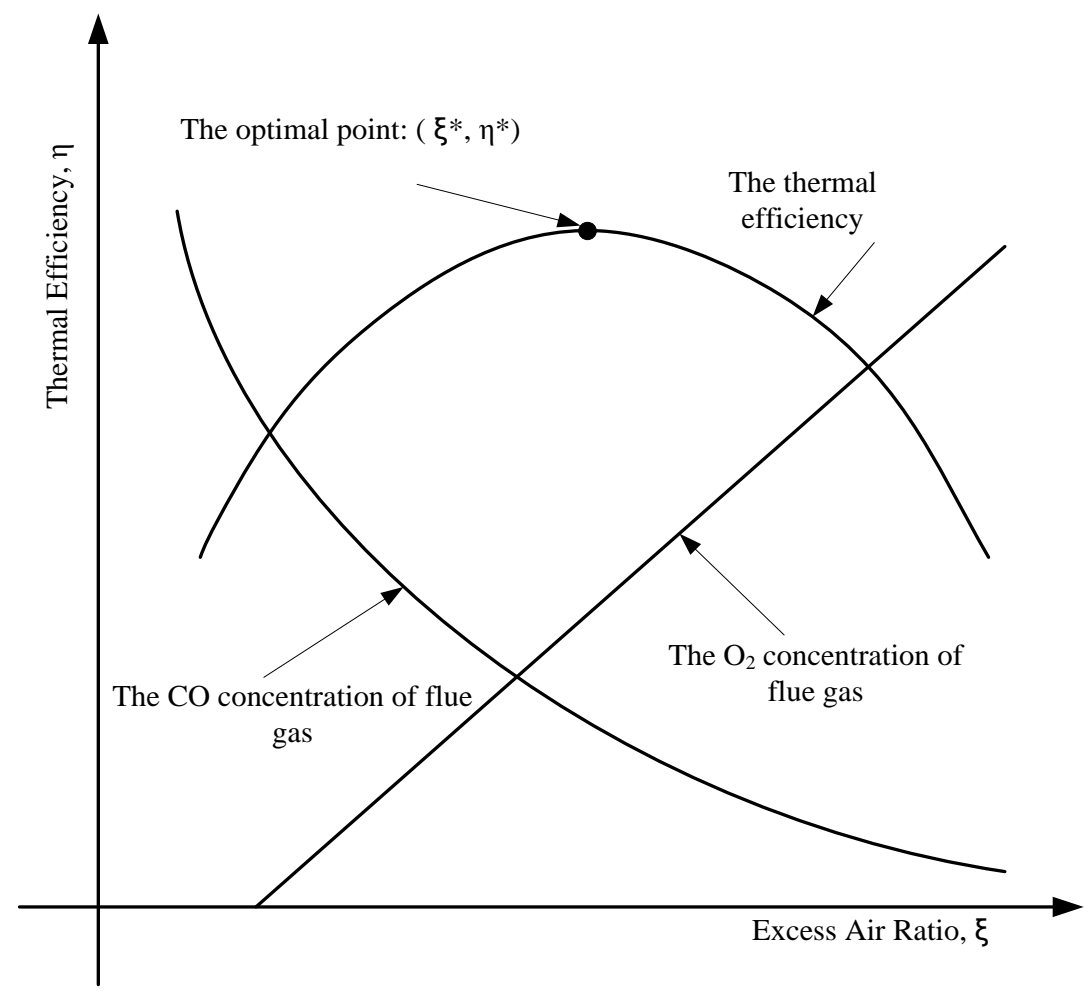

Fig. 1. The thermal efficiency as a function of the excess air ratio.

Based on the report [34], a depiction figure, as seen in Fig. 1, is provided to exhibit the relationship between the thermal efficiency $(\eta)$ and the excess air ratio $(\xi)$. Clearly, the thermal efficiency is unimodal with respect to the excess air ratio. It is accepted in both academia and industry that a maximum $\eta^{*}$ exists under the corresponding optimal excess air ratio $\xi^{*}$. In recent years, this thermal characteristic has drawn much attention to optimize the thermal efficiency of fired heaters, furnaces and boilers, through manipulating the excess air ratio [10-14]. In addition, the excess air affects not only the thermal efficiency, but also operational reliability and environmental impact simultaneously. In practical use, the excess air ratio is indicated by the oxygen concentration of the outlet flue gas, where oxygen concentration instrument is installed. However, due to the difficulty in on-line optimization with dynamic operating conditions, these methods have not achieved wide applications in practice, especially for the limited maintenance resources case. Because, 
(1) The dominant error-based PID control does not work well and often results in large overshoot and long-time disturbance because of frequent control action, especially in the presence of large and frequent changes in thermal load. Moreover, the flue gas - air control system is highly nonlinear with poor sensitivity in the actuators (in many field refineries, the adjustment of inflow air is realized by butterfly valve, and the control of negative pressure is realized by the outlet baffle), which even worsen the control performance, due the control action is not timely realized in high precision.

(2) Although advanced control has been recognized as an effective and feasible approach to the operation of fired heaters, and also model-based control strategies have been developed [7-9] for the purpose of optimal on-line operation of fired heaters. However, it still needs "upper-layer" optimization component to decide the best operating condition for the controller. So far, this optimization layer has been under-explored in both industrial and academic studies. Moreover, model-based control strategies are sensitive to the model and has poor adaptability due to varying but frequent thermal loads and sensor's drift.

In this case, we proposed a practicable control strategy for the flue gas - air system in our previous work to quickly stabilize the operation when confronted with the change in thermal load and eliminate the influence caused by the actuators with poor sensitivity. The core idea is to combine dynamic feedforward control and steady-state feedback control, which significantly reduces the actuator's action frequency and avoids the instability problem of dynamic feedback control while meeting control objectives [15]. The control strategy is out of the scope of this paper; however, for the sake of readability, we will explain it in the following section.

This control strategy provides a foundation, based on which a trial-and-error method was used to search for a better operation point around the vicinity of the current one. Based on the current operating 
point (i.e. the current oxygen concentration set point), an expert rule is implemented to generate a new trial point. This new trial point is realized by the proposed control strategy. The trial value will be treated as the set-point of the control system to be realized. After control system stabilization to the given trial operation point, comparison of the thermal efficiency between the new trial one and the previous one determines the next trial direction. This iterative procedure continues until the defined convergence condition satisfies. However, this simple and local optimization method often takes a long time to find the optimum (if at all) for the processes with frequent fluctuation. This is especially an issue when the process undergoes significant and frequent changes in thermal load and/or large disturbances (such as the pressure changes and component in fuel gas, or other unknown and/or unmeasured noise); under such scenarios the new optimum can be very far from the current operation point.

Against this background, the primary goal of this paper is to extend the optimal control strategy proposed earlier [15] to a more effective strategy for optimizing the thermal efficiency of fired heaters. The novel strategy will combine the stochastic approximation (SA) method with the offline thermal efficiency expert system. This expert system is developed from expert knowledge and historical data by using the state-of-the-art RIMER (belief rule-base inference methodology using evidential reasoning) approach [16]. During on-line operation, the off-line determined initial values are further refined and updated by using SA method to eliminate the influence caused by oxygen instrument drift or the fluctuation of operating condition, e.g., fuel properties. With the help of the offline expert system, the optimal operating set-point can be quickly identified and achieved, especially in the presence of large change in thermal load and can be updated online to maintain better performance and long-term operation autonomously.

This paper proceeds as follows. In section 2, an overview of fired heaters and the thermal efficiency 
are given. Section 3 briefly describes the overall methodology. Section 4 details the various components of the proposed method, including off-line and on-line optimization with control. Case studies are reported in section 5, and concluding remarks are given in section 6.

\section{The process and problem statement}

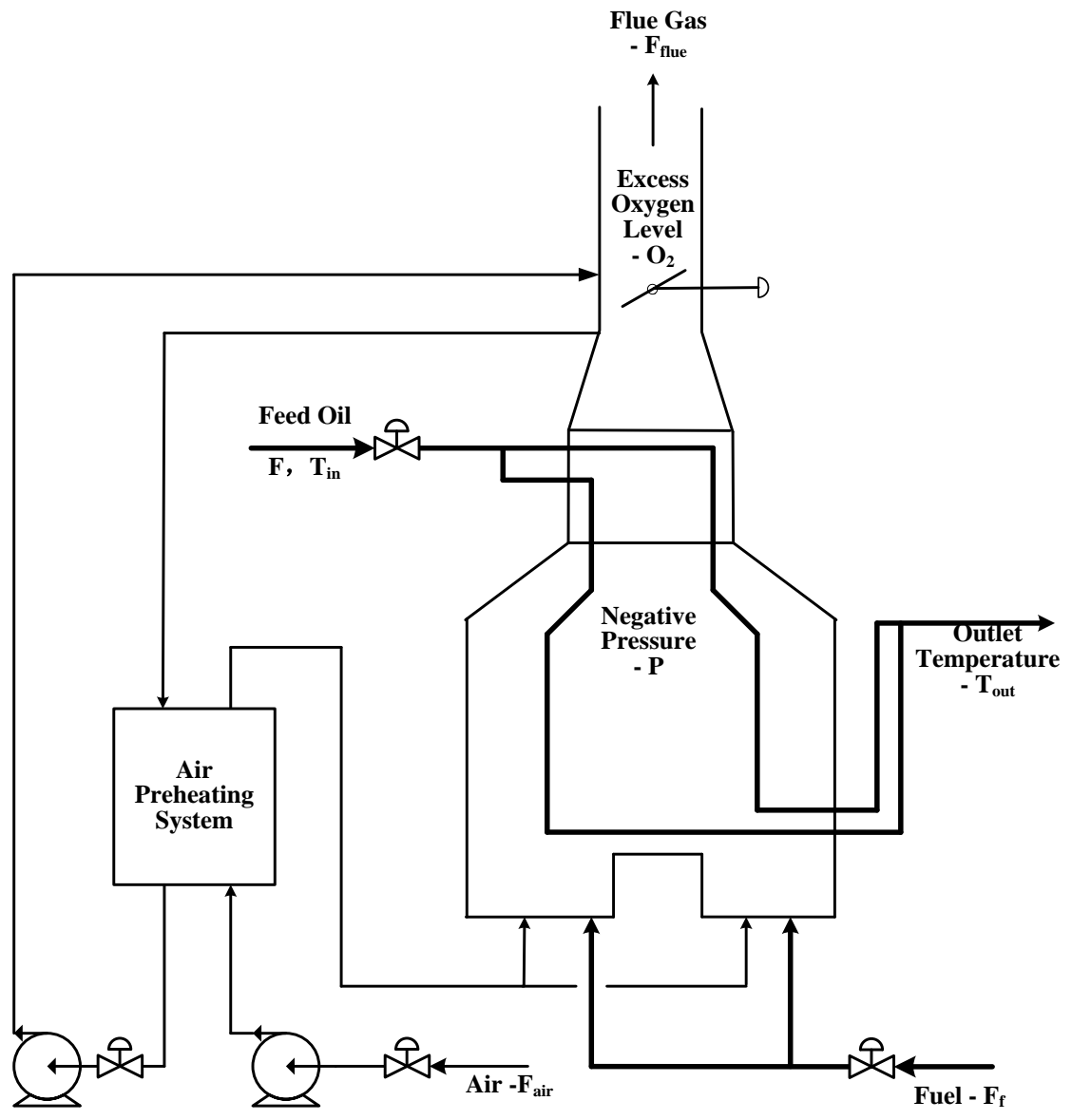

Fig. 2 The schematic of a fired heater.

A typical fired heater is illustrated in Fig. 2. Air from blower with a flowrate $F_{\text {air }}$ is blasted into the combustion chamber after preheated by the flue gas to supply the necessary oxygen for combustion of the fuel (oil, gas, or mix of oil and gas), whose flowrate is $F_{f}$. The feed oil (or other fluids to be heated) with the flow rate $F$ and input temperature $T_{i n}$ is heated in the pipe around the chamber to a desired outlet temperature $T_{\text {out }}$. The emission of flue gas is realized by draught fan or outlet baffle, which also serves 
as the action to adjust the chamber negative pressure $P$. An oxygen analyzer is installed to measure the oxygen concentration $\mathrm{O}_{2}$ as an indicator of combustion state. The objective is to find the corresponding operating condition for the optimal thermal efficiency. And then, the determined operating condition is realized by the control system. As addressed before, excess air ratio is a crucial variable affecting thermal efficiency of fired heaters. Fired heaters need to pursue a suitable excess air ratio for the optimal thermal efficiency. Oxygen concentration in the flue gas is indicative of excess air ratio, and thus usually selected as the operating variable. Hence, the thermal efficiency optimization is equivalent to find an optimal oxygen concentration set point. Online oxygen concentration sensors are vulnerable to the corrosion of high temperature flue gas, which often causes measurement errors and measured value drift. In addition, the load of fired heaters fluctuates frequently, which results in the optimal oxygen concentration set point fluctuation. These factors make it difficult to maintain a satisfactory excess air ratio for optimal thermal efficiency. Seldom strategy is reported for long-term operation. This paper tries to handle these issues and propose a practicable solution.

The thermal efficiency is usually defined as the ratio of the total heat absorbed by the stream being heated (i.e. feed oil in Fig. 2), to the total heat input provided by the fuel [16]. There are two methods for calculating the thermal efficiency: the input-output (also known as direct) method, and the heat-loss (indirect) method [18][19]. The direct method is based on the ratio of the heat absorbed by the heated fluid $\left(Q_{e}\right)$, which can be calculated from the multiplication of flow rate, steam specific heat and the temperature difference (i.e. outlet temperature minus inlet temperature), to the heat input provided by the fuel ( $Q_{f}$, i.e. the multiplication of fuel flow rate and fuel combustion heat on the premise of complete combustion):

$$
\eta=\frac{Q_{e}}{Q_{f}} \times 100 \%
$$


The indirect method is based on mass and energy balance for individual streams. All aspects of heat loss can be estimated according to certain empirical formulas, and the efficiency can be calculated by subtracting the heat loss fractions from $100 \%$. Moreover, the heat losses are due to flue gas, incomplete combustion and other causes. Due different refinery plant heaters with different designs are operated in different conditions, the empirical formula for indirect method thermal efficiency is often refineryspecific. In this paper, only direct method is adopted, so the indirect method is not explained in details. Clearly, the proposed strategy is independent from the detailed thermal efficiency calculation method.

\section{Overview of the proposed optimization and control system}

As described in the aforementioned analysis, demand for thermal load can well reflects the operating states, and it can be adopted as indicator to guide the thermal efficiency optimization. In other words, there will be a set of optimal operating parameters (i.e. thermal efficiency, set points of flue gas oxygen concentration and chamber negative pressure, etc.) depending on the thermal load, and, moreover, varying with different thermal load. Utilizing this, a thermal load partition based optimization strategy is proposed to improve the response and fast arrive at the optimal thermal efficiency point when confronted with varying thermal loads. Firstly, the whole thermal load operation region is portioned into several subregions, in which there is an optimal flue gas oxygen concentration reference value. The partition is realized based on the optimal flue gas oxygen concentration data that is mined from big-data collected from the historical database. Due the partition is out of the scope of this paper, the details are not mentioned and many mature classification methods, such as K-means [20], Neural network [21], are applicable. Then, with the help of the obtained thermal load subregions and the corresponding optimal historical value of flue gas oxygen concentration, we build an expert system to inference the optimal set 
point for flue gas oxygen concentration under a new arrived steady operation state. Furthermore, an online optimizer is run to eliminate the deviation caused by inference inaccuracy and oxygen instrument drift. The optimal reference set point from the offline expert system is good enough, so the thermal efficiency can be fast tuned to a near optimal state, which largely reduces the optimization procedure.

Fig. 3 depicts the general structure of the thermal efficiency optimization system. This strategy is based on the data collected from the plant distributed control system (DCS) through the OLE (object linking and embedding) for process control (OPC) communication interface. During operation, the corresponding optimal value of flue gas oxygen concentration is controlled quickly as entering a new specified thermal load. The plant is constantly monitored in terms of whether it is in a steady state. The steady state or not is determined through a combined analysis of variance of thermal load, fuel flow and feed flow. As soon as the process reaches a steady state, the on-line SA self-optimization component is activated to refine and update further corresponding optimal value of flue gas oxygen concentration. The first step in on-line optimization is to find good initial values using the RIMER method. This initialization step is supported by an off-line multi-regional BRB component, developed from the database and knowledge base established by the field experts. The BRB is re-trained and updated offline when sufficient new data are collected through OPC. Then, the second step is to use the SA "selfoptimization" method to further refine the optimal operation point. This two-step approach fully exploits the prior knowledge about the process, so that the optimum can be quickly found and refined by reliable SA "self-optimization" on the condition of steady state ; this is in contrast to the previously reported study in which only an on-line self-optimization component was used [15]. Moreover, the refined new optimum set point is utilized to update the inferential value in the off-line multi-regional BRB. 


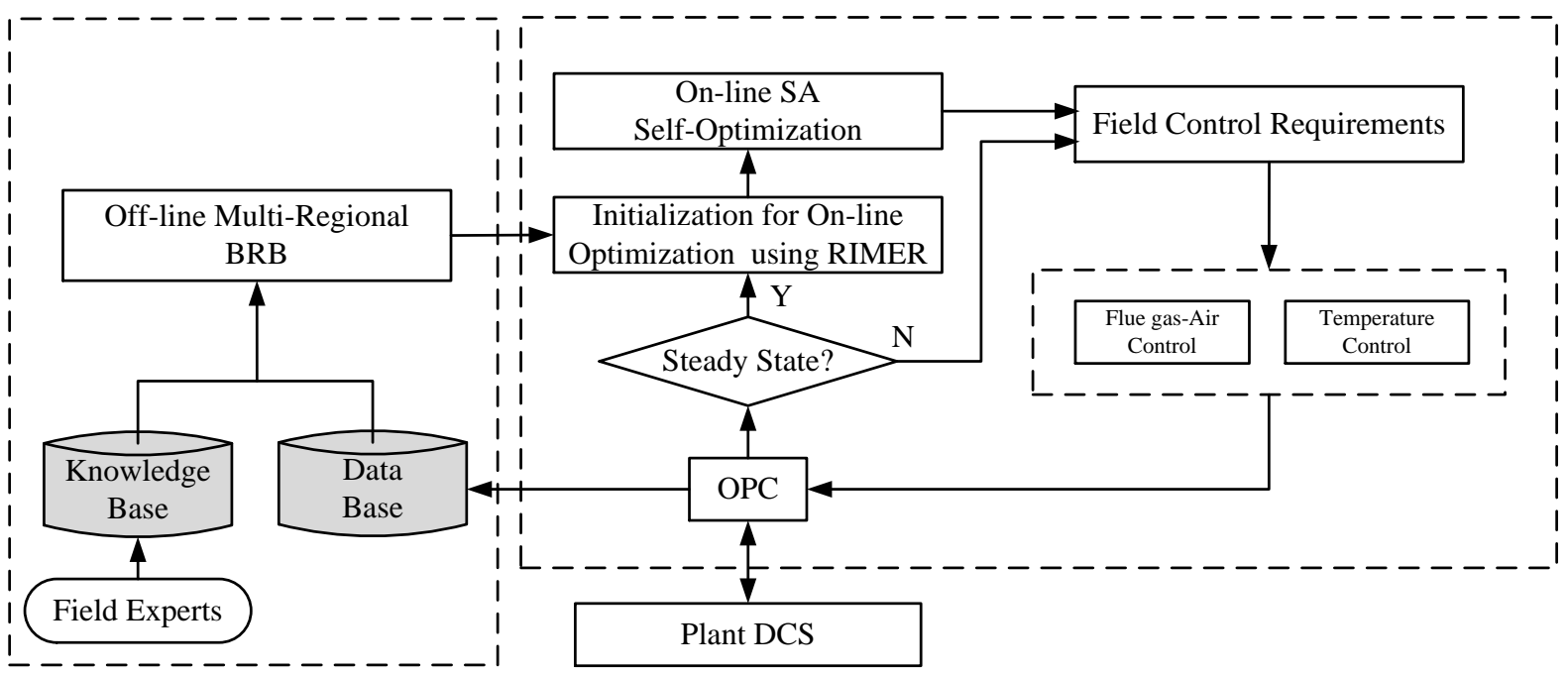

Fig. 3 The proposed optimization and control system

Finally, the determined optimal operation point is implemented through a practical control strategy for the flue gas - air system, which is applied to the flue gas oxygen concentration and chamber negative pressure control on the basis of flue gas-air control system. A detailed description of the various components in the proposed system is presented in the subsequent section. Meanwhile, a subordinate temperature controller works to control the outlet temperature of the heated steam or fluid (feed oil in this case study) to a desired set point. Taking the fuel flowrate as the manipulated variable and the outlet temperature as controlled variable, model predictive control is utilized to stabilize the fuel flowrate as fast and smooth as possible, which benefits the fuel gas-air control system. The temperature control has been published in our previous report, so we do not explain this part in details. More details can refer to our published reports $[35,36]$.

\section{Belief rule-based on-line optimization of thermal efficiency}

\subsection{Off-line multi-regional intelligent optimization using the RIMER approach}

The thermal load can be calculated as follows,

$$
Q_{e}=m_{f d} H_{f d}
$$


where $Q_{e}$ is efficient thermal load, $m_{f d}$ is mass flow rate of feed, $H_{f d}$ is enthalpy value of feed. Because there is no phase transition in this case, the enthalpy value of the feed oil is the multiplication of feed oil specific heat and the temperature difference (outlet temperature minus inlet temperature), so the feed temperature is well considered.

This multi-region phenomenon motivated the development of the knowledge and data base. According to the historical data and field engineers' experience, the operation is usually classified to 4 $\sim 8$ subregions, with a specific set of the historical optimal operation parameters (in terms of oxygen concentration, $\mathrm{O}_{2}$ and negative pressure, $P$ ) related with each individual subregion. But negative pressure $P$ controlled zone is loose in the field and the control is coupled with oxygen concentration control, so it is only used as a disturbing variable if out of controlled zone. Fig. 4 illustrates an off-line multi-region database constructed based on the efficient thermal load of a fired heater.

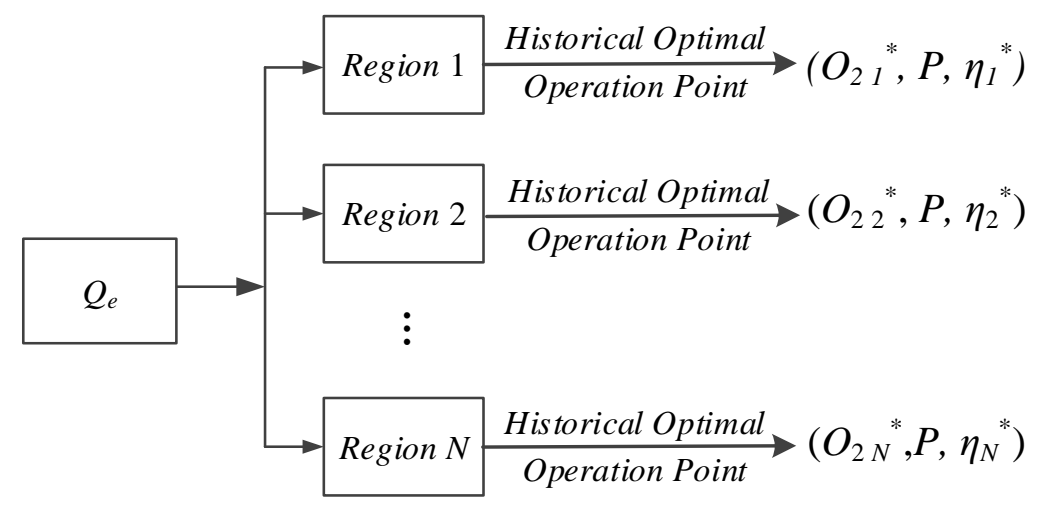

Fig. 4. The off-line multi-region database

In this paper, the database is constructed using the RIMER approach. In comparison with the traditional IF-THEN rule-base, RIMER provides a more informative and flexible representation of knowledge; it is capable of capturing vagueness, incompleteness, and nonlinear causal relationships [16]. In recent years, RIMER has been successfully applied to the safety analysis of off-shore systems [22], pipeline leak detection [23-25], clinical decision support systems [26], stock trading expert systems [27] and delayed coking unit operation expert system [28]. It is more adaptable to data analysis and mining 
for big-data.

In the paper, a BRB consists of belief rules defined as follows:

$$
\begin{aligned}
& l_{k}: \operatorname{IF} Q_{e} \in R_{k} \text { Then } O_{2} \text { is }\left\{\left(D_{1}, \beta_{1 k}\right),\left(D_{2}, \beta_{2 k}\right), \cdots\left(D_{N}, \beta_{N k}\right)\right\} \\
& \text { with a weight for this rule } \theta_{k}, k=1,2, \cdots L .
\end{aligned}
$$

where $l_{k}$ denotes the $k$ th rule, $R_{k}$ is the subregion of the input $Q_{e}$, and $\beta_{i k}(i=1,2, \cdots N)$ is the belief degree of the rank $D_{i}$ for the optimal flue gas oxygen concentration $O_{2}$. Specific to this study, one rule is designed for each operating subregion, and the rule weight $\theta_{k}$ is introduced to describe the credibility of this particular rule. Note that the belief degree $\beta_{j k}$ and the relative weight $\theta_{k}$ are initiated according to expert knowledge and data analysis, and then can be trained with dedicated learning algorithms from operation data. The training algorithm proposed by $\mathrm{Si}$ was adopted in this study [29].

By using the rule transformation technique, the input data $Q_{e}$ can be described as a distribution on referential values using a belief structure as follows,

$$
\left\{\left(R_{1}, \alpha_{1}\right),\left(R_{2}, \alpha_{k}\right), \cdots\left(R_{L}, \alpha_{L}\right)\right\}
$$

where $R_{k}$ is the subregion of the input $Q_{e}, \alpha_{k}$ is the matching degree to which subregion it belongs to. $\alpha_{k}$ could be obtained using different ways of rule-based transformation technique $[16,30]$. In this study, it is calculated using the referential value $A_{k}$ of $Q_{e}$ in $R_{k}$. Taking one input $Q_{e}$, if $Q_{e} \in\left[A_{k-1}, A_{k}\right)$, then $\alpha_{k-1}=\left(Q_{e}-A_{k-1}\right) /\left(A_{k}-A_{k-1}\right)$ and $\alpha_{k}=\left(A_{k}-Q_{e}\right) /\left(A_{k}-A_{k-1}\right)$.

Subsequently, $\alpha_{k}$ is combined with the rule weight $\theta_{k}$ to obtain the so-called "activation weight" as follows:

$$
\omega_{k}=\frac{\theta_{k} \alpha_{k}}{\sum_{i=1}^{L} \theta_{i} \alpha_{i}}
$$

A BRB can thus be summarized using a belief rule expression matrix shown in Table 1. 
Finally, based on the above BRB, the evidential reasoning algorithm [31] can be used to generate the appropriate value of flue gas oxygen concentration as follows:

$$
\begin{gathered}
\hat{O}_{2}=\left\{\left(D_{j}, \hat{\beta}_{j}\right), j=1, \cdots, N\right\}=\sum_{j=1}^{N} D_{j} \hat{\beta}_{j} \\
\hat{\beta}_{j}=\frac{\mu\left[\prod_{k=1}^{L}\left(\omega_{k} \beta_{j k}+1-\omega_{k} \sum_{i=1}^{N} \beta_{j k}\right)-\prod_{k=1}^{L}\left(1-\omega_{k} \sum_{i=1}^{N} \beta_{j k}\right)\right]}{1-\mu\left[\prod_{k=1}^{L}\left(1-\omega_{k}\right)\right]}, j=1, \cdots, N \\
\mu=\left[\sum_{i=1}^{N} \prod_{k=1}^{L}\left(\omega_{k} \beta_{j k}+1-\omega_{k} \sum_{i=1}^{N} \beta_{j k}\right)-(N-1) \prod_{k=1}^{L}\left(1-\omega_{k} \sum_{i=1}^{N} \beta_{j k}\right)\right]^{-1}
\end{gathered}
$$

where $\hat{O}_{2}$ is the predicted optimal flue gas oxygen concentration, and $\hat{\beta}_{j}$ is the predicted belief

\begin{tabular}{|c|c|c|c|c|c|c|c|c|}
\hline \multirow{2}{*}{$\begin{array}{l}\text { Rule } \\
\text { No. }\end{array}$} & \multirow{2}{*}{$\begin{array}{c}\text { Rule } \\
\text { Weight }\end{array}$} & \multirow{2}{*}{ Input } & \multicolumn{6}{|c|}{ Output } \\
\hline & & & $D_{1}$ & $D_{2}$ & $\ldots$ & $D_{k}$ & $\ldots$ & $D_{N}$ \\
\hline 1 & $\theta_{1}$ & $R_{1}$ & $\beta_{11}$ & $\beta_{12}$ & $\ldots$ & $\beta_{12}$ & $\ldots$ & $\beta_{1 N}$ \\
\hline 2 & $\theta_{2}$ & $R_{2}$ & $\beta_{21}$ & $\beta_{22}$ & $\ldots$ & $\beta_{2 k}$ & $\ldots$ & $\beta_{2 N}$ \\
\hline$\vdots$ & $\vdots$ & $\vdots$ & $\vdots$ & $\vdots$ & $\vdots$ & $\vdots$ & $\vdots$ & $\vdots$ \\
\hline$i$ & $\theta_{i}$ & $R_{i}$ & $\beta_{i 1}$ & $\beta_{i 2}$ & $\ldots$ & $\beta_{i k}$ & $\ldots$ & $\beta_{i N}$ \\
\hline$\vdots$ & $\vdots$ & $\vdots$ & $\vdots$ & $\vdots$ & $\vdots$ & $\vdots$ & $\vdots$ & $\vdots$ \\
\hline$L$ & $\theta_{L}$ & $R_{L}$ & $\beta_{L 1}$ & $\beta_{L 2}$ & $\ldots$ & $\beta_{L k}$ & $\ldots$ & $\beta_{L N}$ \\
\hline
\end{tabular}
degree in rank $D_{j}$. Note that $\hat{\beta}_{j}$ is the function of $\alpha_{k}, \theta_{k}$ and $\beta_{j k}$.

Table 1 The BRB represented in a belief rule expression matrix.

The obtained flue gas oxygen concentration will be used as the initial value for on-line optimization, as discussed in Section 4.2.

\subsection{On-line self-optimization}

The online oxygen concentration sensor drift definitely have a significant impact on thermal efficiency, due the oxygen concentration sensor drift will make the historical optimal oxygen 
concentration operation parameters in subregions invalid for use.. Moreover, the influence caused from the sensor drift is the main challenge for industrial application use. In this case, the online optimization is needed to update the historical optimal oxygen concentration operation parameter in current region to maintain a long-term effective use of the thermal efficiency optimization.

The stochastic approximation (SA) is a gradient algorithm suitable for simple search problems, based on a similar expression with quasi-Newton methods. By generating one perturbation point, the gradient information can be calculated as follows:

$$
\left.\frac{\partial \eta}{\partial O_{2}}\right|_{o_{i}} \approx g_{i}=\frac{\eta\left(O_{2_{i}}\right)-\eta\left(O_{2_{i}}-c_{i} \Delta_{i}\right)}{c_{i} \Delta_{i}}
$$

where $\eta$ is thermal efficiency, $\mathrm{O}_{2}$ is flue gas oxygen concentration. $O_{2}$ is the current steady point. $\Delta_{i}$ is the base perturbation variable and often determined as half of the subregion interval, $c_{i}$ is the gain for perturbation at the $i$ th iteration, $c_{i} \Delta_{i}$ is the actual perturbation.

Then the next steady point $O_{2 i+1}$ is generated by:

$$
O_{2_{i+1}}=O_{2_{i}}+a_{i} g_{i}
$$

where $g_{i}$ is gradient given by (9), $a_{i}$ is the gain at the $i$ th iteration.

The gain sequences are given by (11-12),

$$
\begin{gathered}
c_{i}=\frac{c}{(i+1)^{\gamma}} \\
a_{i}=\frac{a}{(b+i+1)^{\tau}}
\end{gathered}
$$

where usually $\tau$ and $\gamma$ are taken to be 0.602 and 0.101 , respectively. Then, the parameters $a, b$ and $c$ are chosen together to ensure effective practical performance, and a larger $a$ and $c$ may enhance performance in the later iterations by producing a larger step size when the effect of $b$ is small. These values are selected based on the recommendation proposed in [32]. Based on the parameters selection guidance in [32], a, b, and c are adopted as $1.22,15$, and 0.1 respectively in this paper. 
The algorithm terminates if the change in thermal efficiency is less than a threshold, which was chosen as $\sigma$ in this study. That is to say, the online optimization terminates once $\left|\eta_{i}-\eta_{i-1}\right| \leq \sigma$ satisfies.

As discussed in Section 3, the SA method is initiated with a good starting point $O_{2}^{0}$ determined by the BRB expert system. The optimal value $O_{2}^{*}$, searched by SA, will be used to update the referential values of subregions. It could have bias from $O_{2}^{0}$ given by BRB, and then we adjust the referential values appropriately as follows:

$$
D_{j, \text { new }}=D_{j}+O_{2}^{*}-O_{2}^{0}
$$

\subsection{Control for the flue gas - air system}

Oxygen concentration is of vital importance to the thermal efficiency. However, the error-based PID set-point control does not work well in this case and it often results in large overshoot and long-time disturbance because of frequent control action. Moreover, in many field refineries, the adjustment of inflow air is realized by butterfly valve but not the air blast with variable frequency, and the control of negative pressure is realized by the outlet baffle but not the draught fan. The long-stroke actuators (i.e. outlet baffle and butterfly valve) possess poor sensitivity, because of large dead zones, lag and so on, which even worse the control performance, due the control action is not timely realized in high precision. Although the model-based control (such as model predictive control and so on) is somewhat robust to the model, in field applications, model-based control cannot guarantee a long-term operation because of frequent control action and often has a high maintenance cost. In this case, we addressed a practicable control strategy for the flue gas - air system to realize the optimized flue gas oxygen concentration $\mathrm{O}_{2}$ and negative pressure $P$. This strategy utilizes a mechanistic model for feedforward control at dynamic 
state, and feedback control at steady-state. That is, in details, feedforward control works during dynamic transition process and feedback control actives once the system arrives at a steady state. It can effectively reduce the risk caused by high frequency adjustment. The sufficient condition for convergence was previously established [33]. For the sake of readability, the detailed mechanistic model for both dynamic and steady state and the convergence proof are exhibited in the Appendix, although these works have been published in Chinese journals before.

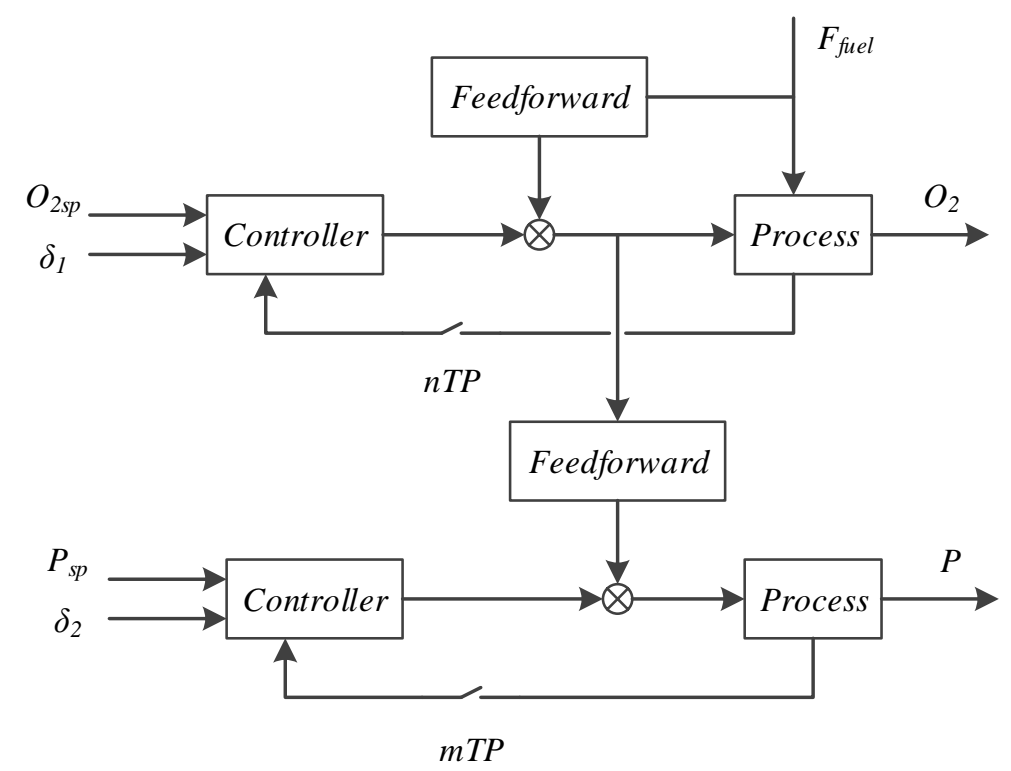

Fig. 5. The control strategy for the flue gas - air system

As shown in Fig.5, $T P$ is the control period, $n T P$ is the steady state control period of $O_{2}, m T P$ is the steady state control period of $P$. An output zone goal with a set-point is employed in the $O_{2}$ or $P$ control. The flue gas oxygen concentration $\mathrm{O}_{2}$ is in feedforward control of fuel gas at dynamic state, and feedback control of zone goal $\left[O_{2 s p}-\delta_{1}, O_{2 s p}+\delta_{1}\right]$ at steady-state. The negative pressure $P$ is in feedforward control of fuel gas at dynamic state, and feedback control of zone goal $\left[P_{s p}-\delta_{2}, P_{s p}+\delta_{2}\right]$ at steady-state.

\section{Case studies}

This section presents two case studies with the optimization strategy proposed above. The first case shows the simulation results of a fired heater on UniSim ${ }^{\mathrm{TM}}$ Design platform. The second case is the field 
application results at a real oil refinery using this thermal efficiency optimization strategy.

\subsection{Simulation results}

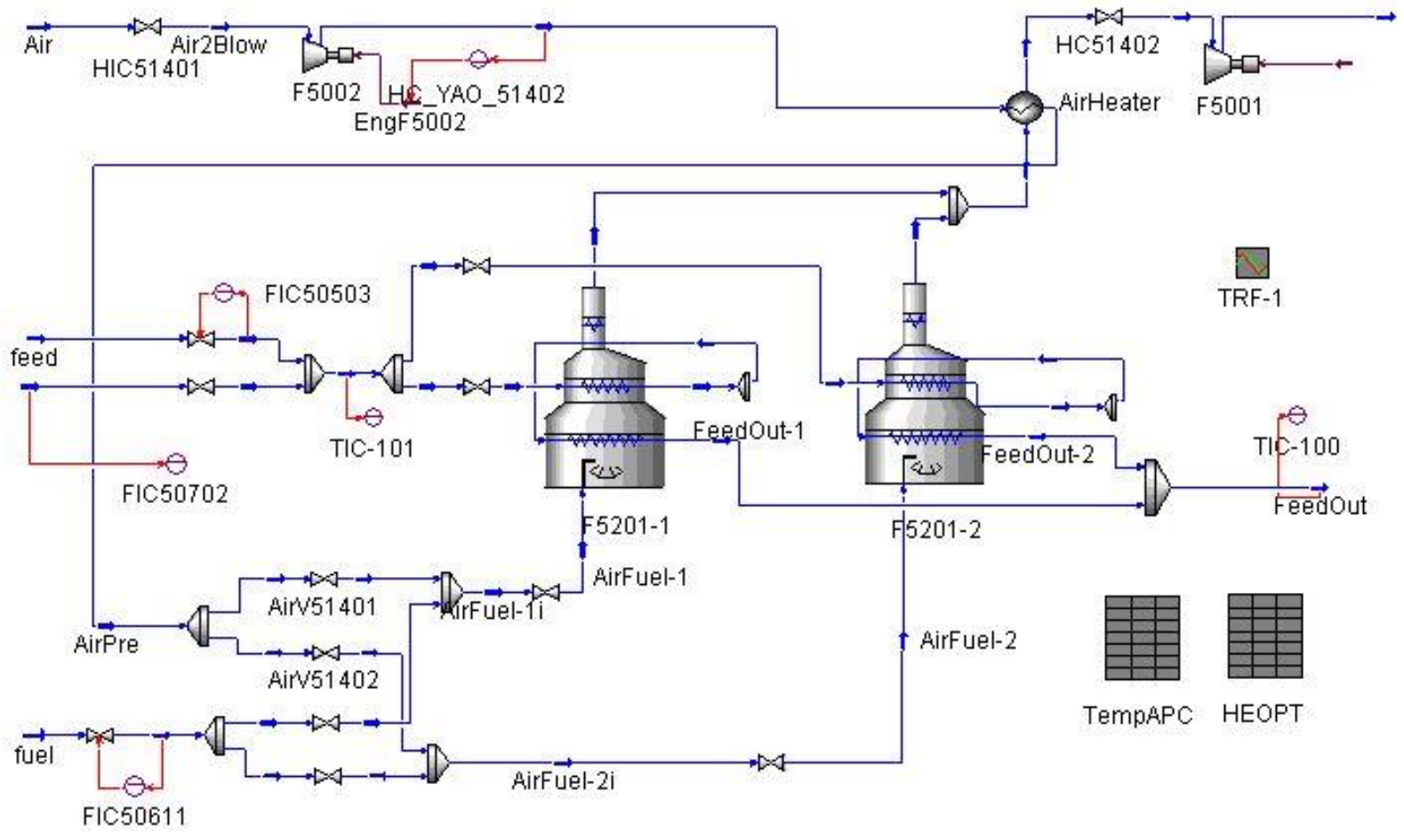

Fig.6. The flowsheet of a fired heater simulated on UniSim ${ }^{\mathrm{TM}}$ platform.

In order to verify the thermal efficiency optimization expert system proposed in this paper, a simulated fired heater was constructed on the UniSim ${ }^{\mathrm{TM}}$ Design platform as shown in Fig. 6, which is customized to replicate the actual 1.2Mt/a diesel hydrogenation unit (DHU) and operate effectively in real-time. The fired heater is a two-chamber structure. In this case study, under the temperature control and the flue gas - air control, the system's steady data are collected working in different load regions (by changing the flow of feed) and different flue gas oxygen concentration $O_{2}$ (by adjusting the $O_{2}$ set point). Then the partition is realized as shown in Table 2 . The referential thermal load points are defined for the input loads being quantified as $\alpha_{k}$ in BRB. 
Table 2 Referential points for thermal load and flue gas oxygen concentration

\begin{tabular}{llllll}
\hline & I & II & III & IV & V \\
\hline$Q_{e}(M W)$ & 5.93 & 5.49 & 5.15 & 4.81 & 4.37 \\
$O_{2}^{*}(\%)$ & 2.0 & 2.5 & 3.2 & 3.8 & 4.3 \\
\hline
\end{tabular}

To build the initial BRB, five rules are extracted by examining off-line multi-region database and using field engineers' experiences, as shown in Table 3. For this case study, five subregions partition solution is determined using the cluster method. The initial belief degrees $\beta_{i k}$ in BRB are determined by the expert knowledge and data analysis. For example, if $Q_{e}$ is in $R_{2}$, the expert judges that the possibility of the optimal flue gas oxygen concentration in rank $D_{2}$ is bigger than others. With the aid of statistical information, it is assessed that the belief degree to $D_{l}$ is 0.1 and the belief degree to $D_{2}$ is 0.9 . The initial rule weights $\theta_{k}$ can be all set to 1 . After this, the BRB can be run.

Table 3 BRB provided by examining the simulation data

\begin{tabular}{|c|c|c|c|c|c|c|c|}
\hline \multirow{2}{*}{$\begin{array}{l}\text { Rule } \\
\text { No. }\end{array}$} & \multirow{2}{*}{$\begin{array}{c}\text { Rule } \\
\text { Weight }\end{array}$} & \multirow{2}{*}{$Q_{e}$} & \multicolumn{5}{|c|}{$\beta$} \\
\hline & & & $D_{1}$ & $D_{2}$ & $D_{3}$ & $D_{4}$ & $D_{5}$ \\
\hline 1 & 1 & $R_{1}$ & 1 & 0 & 0 & 0 & 0 \\
\hline 2 & 1 & $R_{2}$ & 0.10 & 0.90 & 0 & 0 & 0 \\
\hline 3 & 1 & $R_{3}$ & 0 & 0 & 0.98 & 0.02 & 0 \\
\hline 4 & 1 & $R_{4}$ & 0 & 0 & 0 & 0.98 & 0.02 \\
\hline 5 & 1 & $R_{5}$ & 0 & 0 & 0 & 0 & 1 \\
\hline
\end{tabular}

Then the parameter training algorithm is used to train the BRB built above, and the trained BRB is shown in Table 4. 
Table 4 Trained BRB

\begin{tabular}{|c|c|c|c|c|c|c|c|}
\hline \multirow{2}{*}{$\begin{array}{l}\text { Rule } \\
\text { No. }\end{array}$} & \multirow{2}{*}{$\begin{array}{c}\text { Rule } \\
\text { Weight }\end{array}$} & \multirow{2}{*}{$Q_{e}$} & \multicolumn{5}{|c|}{$\beta$} \\
\hline & & & $D_{l}$ & $D_{2}$ & $D_{3}$ & $D_{4}$ & $D_{5}$ \\
\hline 1 & 0.943 & $R_{1}$ & 0.715 & 0.117 & 0.168 & 0 & 0 \\
\hline 2 & 0.999 & $R_{2}$ & 0 & 0.896 & 0.104 & 0 & 0 \\
\hline 3 & 0.977 & $R_{3}$ & 0 & 0.082 & 0.918 & 0 & 0 \\
\hline 4 & 0.943 & $R_{4}$ & 0 & 0.117 & 0.167 & 0.716 & 0 \\
\hline 5 & 0.943 & $R_{5}$ & 0 & 0.117 & 0.167 & 0 & 0.716 \\
\hline
\end{tabular}

In this simulation study, two cases, i.e. the case under varying thermal loads and the case under sensor's drift, are considered to demonstrate the effectiveness.

\section{(1) Simulation results under varying thermal loads}

Figs. 7-9 summarize the results of the three operation strategies as described below. For all three simulation scenarios, the same thermal load changes are used.

In the first scenario, no optimization is applied and only controllers (described in Section 4.3) are used. The operation performance under thermal load changes is shown in Fig. 7. 

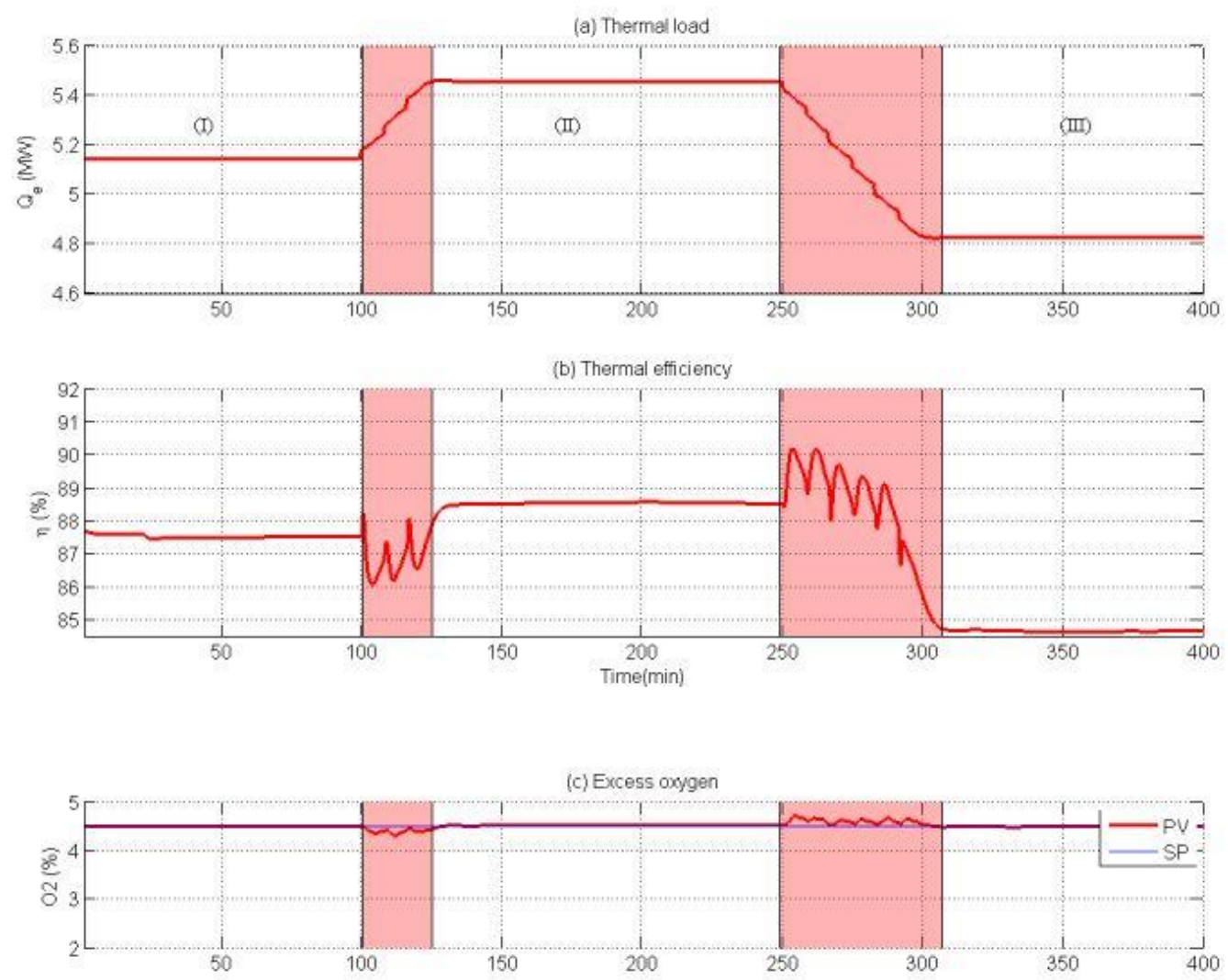

(d) Negative pressure
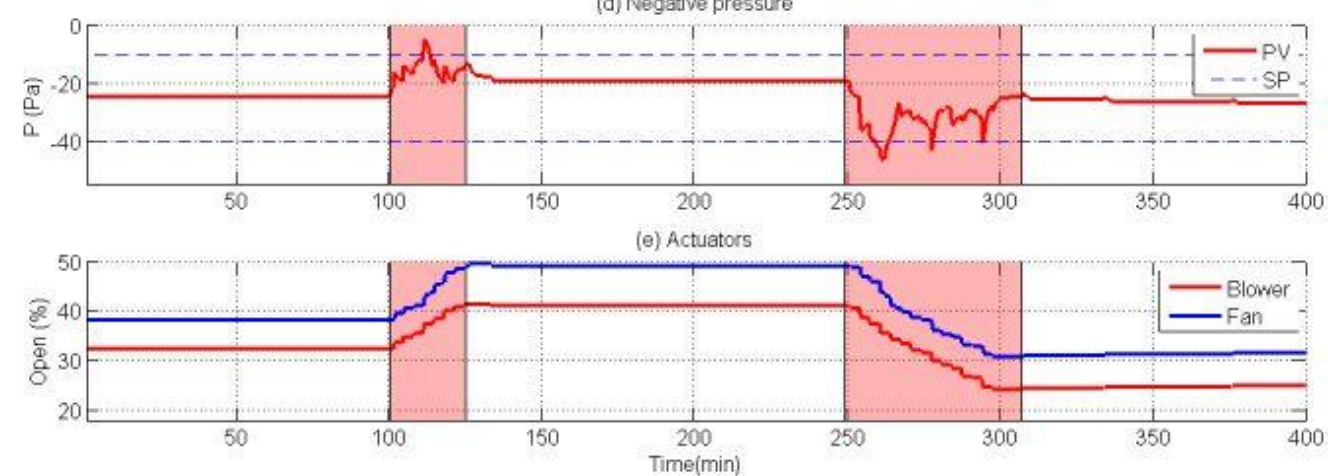

Fig.7. The operation results with no optimization. (a): thermal load; (b) thermal efficiency; (c) excess oxygen; (d) negative pressure; (e) actuators.

Fig. 7(a) shows the three consecutively changed thermal loads, i.e. 5.15MW, 5.46MW and 4.83MW respectively. The shaded areas correspond to the transition from one thermal load to another, which is not under our consideration with regard to optimization (see Sections 3 and 4 for discussion of this matter). Therefore, we focus on the three steady state stages: Stage I (0-100min), II (125-250min) and III (308-400min) in Fig. 7. Fig. 7(b) exhibits the thermal efficiency fluctuation under varying thermal loads, where the thermal efficiency are on average $87.54 \%$ (Stage I), $88.53 \%$ (Stage II), and $84.7 \%$ 
(Stage III) respectively. Fig. 7(e) shows the move of actuators (blower and induced draft fan) whose objective is to stabilize the oxygen concentration and chamber negative pressure (see Fig. 7(c) and (d)). Zone control strategy is adopted for negative pressure control to reduce the risk of frequent control actions caused by the set-point control methods, and feedback control action is generated to move the actuator only when the measured pressure exceeds the defined limits. Hence, the pressure exceeds the limits at some time points in Fig. 7(d). However, we can also see that the pressure can be quickly pulled back into the limits once it exceeds the limits.

In the second scenario, in addition to using the same control strategy as in the first case, we incorporated the RIMER in the system to guide the optimization of thermal efficiency, as shown in Fig. 8. The RIMER expert system was built as Table 1 by using the simulation data. Fig. 8(b) shows the thermal efficiency curves optimizing process. It is clear that three optimizing procedures are obtained when confronted with three thermal load changes depicted in Fig. 8(a), which is $88.47 \%$ for stage I, 91.27\% for stage II and $86 \%$ for stage III. Comparing with the first scenario in which no optimization was used, the use of the RIMER approach increases the thermal efficiency by $0.93 \%, 2.74 \%$ and $1.3 \%$ for the three stages, respectively. That is to say, it will reduce cost about $16,139.4$ dollars one year in practice. A more remarkable profit gain will be resulted if this strategy is run on a larger size fired heater. 

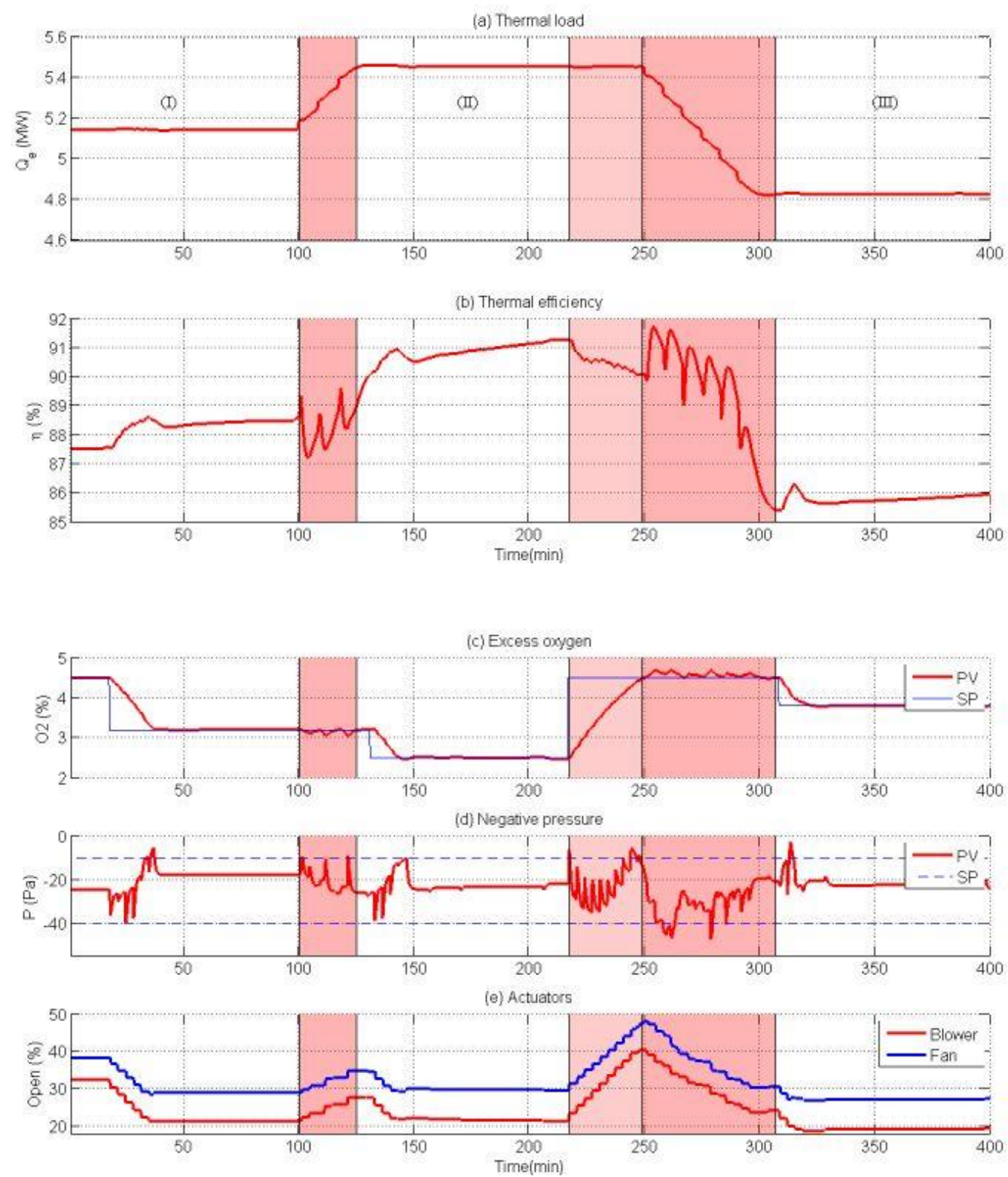

Fig.8. The operation results with RIMER. (a): thermal load; (b) thermal efficiency; (c) excess oxygen; (d) negative pressure; (e) actuators.

With the help of RIMER, the optimal set point for oxygen concentration is given at $3.2 \%$ for stage

I, while sets are given at $2.6 \%$ and $3.8 \%$ in the following two stages respectively shown in Fig. 8(c).

Comparing with the first scenario, a descending set point for oxygen concentration is obtained. That is to say, the system arrives at a lower excess air ratio. This indicates that the heat loss in flue gas is decreased.

At last, the proposed online optimizer is involved to furthermore improve the optimizing effect. 
The resulted thermal efficiency optimizing process is depicted in Fig. 9.
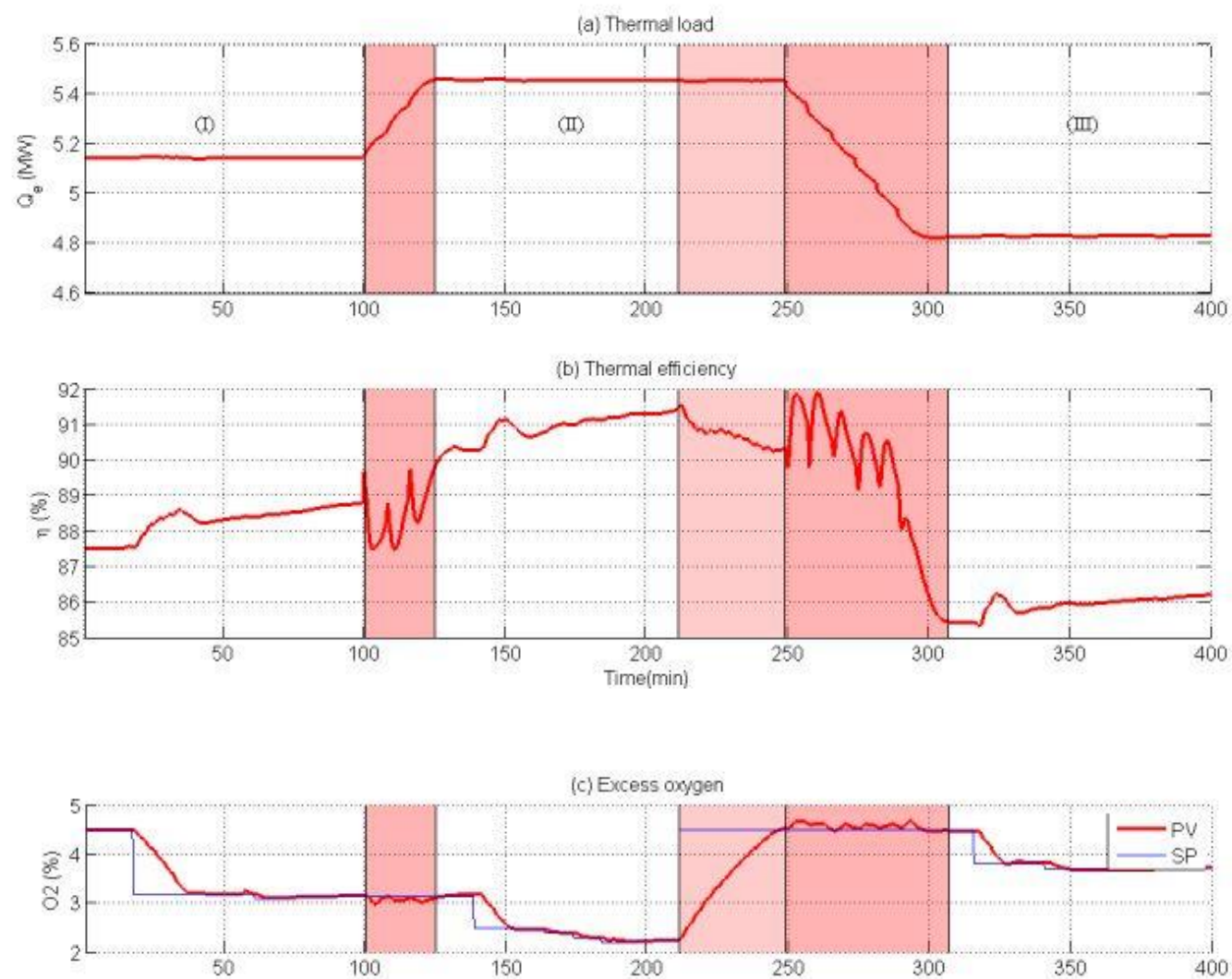

(d) Negative pressure

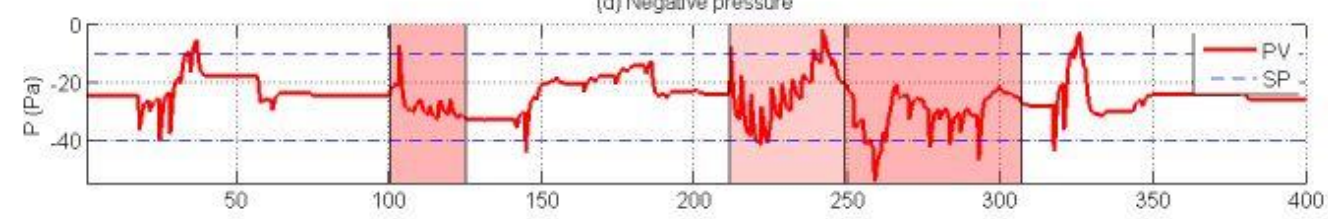

(e) Actuators

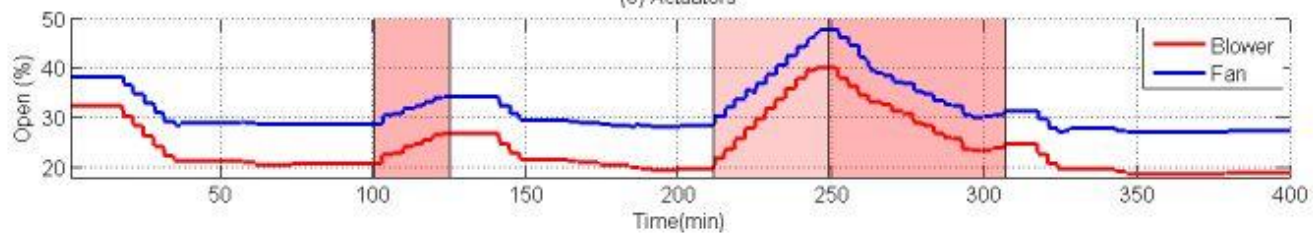

Fig.9. The operation results with RIMER. (a): thermal load; (b) thermal efficiency; (c) excess oxygen; (d) negative pressure; (e) actuators.

The thermal efficiency changing details are given in Fig. 9(b). Similar with the result in Fig. 8(b), three optimal stages are obtained in this scenario. A thermal efficiency $88.79 \%$ is obtained for thermal load change in stage I, and $91.36 \%$ and $86.22 \%$ for stage II and III respectively. Under the on-line optimizer, a further adjustment is obtained based on the near-optimal point given by RIMER. Comparing with the result of RIMER based optimization, a further increase, $0.32 \%, 0.09 \%$ and $0.22 \%$ is obtained 
for these three stages respectively. Fig. 9(c) provides the adjusting curve for oxygen concentration. In this scenario, the set points for oxygen concentration are tuned to $3.1 \%$ (Stage I), $2.4 \%$ (Stage II) and $3.7 \%$ (Stage III). The further improvement for thermal efficiency is arrived due to the lower heat loss indicated by the oxygen concentration set point.

\section{(2) Simulation results under sensor's drift}

As we all known, online oxygen concentration sensors are vulnerable to the corrosion of high temperature flue gas. The measurement errors and measured value drift is hard to be detected and thus brings difficulties for thermal efficiency optimization. In this scenario, we design an experiment in which the oxygen concentration sensor has a $-1.0 \%$ drift to illustrate the solution's effectiveness.

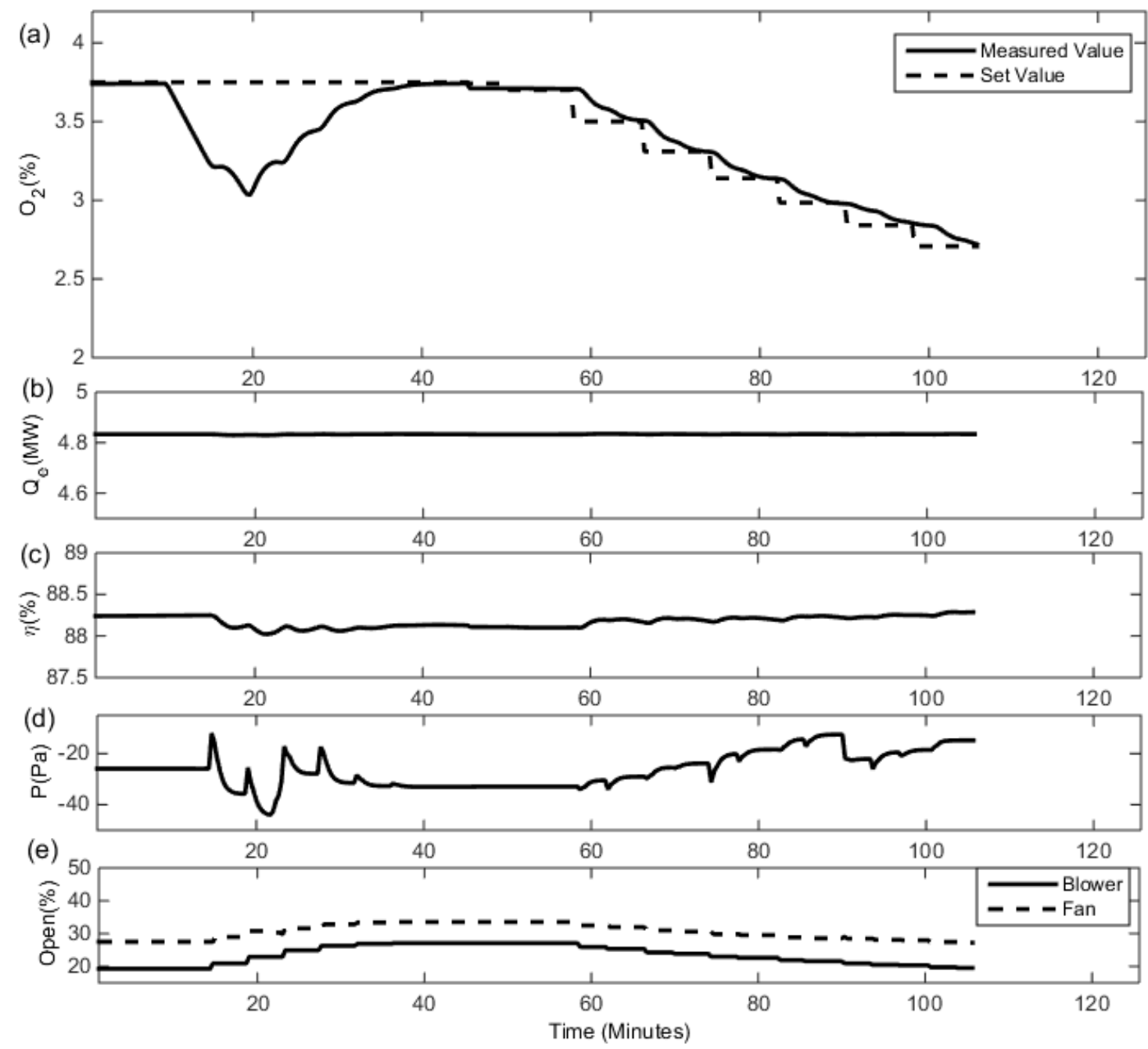

Fig. 10. The operation results with RIMER under sensor's drift. (a):oxygen set value and measured value; (b) thermal load; (c) thermal efficiency; (d) negative pressure; (e) actuators. 
Initially, the system run at its optimal state with the thermal efficiency $88.24 \%$ and the oxygen concentration sensor's indication $3.71 \%$. From the 10th minute, the sensor's drift happens. That is to say, the measured oxygen concentration value is under-measured than its true value. To track the set value, the flue-gas control system then increase the inlet air amount. From the 15th minute, the control action results in the thermal efficiency drop. At 40th minute, the system reach a new steady state with the thermal efficiency at $88.02 \%$ level. Until 58th minute, the oxygen concentration set value (i.e. the dot line in Fig. 10 (a)) does not change and maintains a historically optimal reference value. From 58th minute, the SA based online optimization is actuated. After six steps, the final thermal efficiency returns at its $88.25 \%$ level. However, the oxygen concentration set value is then at $2.7 \%$. The resulted set value, i.e. $2.7 \%$ here, is then updated in offline RIMER system. In this way, the influence by the sensor's drift is compensated.

\subsection{Field application}

This novel and practical on-line optimization method for the thermal efficiency of fired heaters has been also implemented in a real refinery in China. In the practical implementation, the measured pressure and fuel gas flowrate are processed with a low pass filter. Fig. 11 illustrates the thermal efficiency optimization performance of fired heaters of $5 \mathrm{Mt} / \mathrm{a}$ unit. It is demonstrated that the on-line optimization system proposed in this paper works well in field applications.

In the case, we also use five subregions and the referential points are defined in Table 5.

Table 5 Referential points of thermal load

\begin{tabular}{llllll}
\hline & $\mathrm{I}$ & $\mathrm{II}$ & $\mathrm{III}$ & $\mathrm{IV}$ & $\mathrm{V}$ \\
\hline$Q_{e}(M W)$ & 23 & 21 & 20 & 19 & 17 \\
$O_{2}{ }^{*}(\%)$ & 2.03 & 2.91 & 3.74 & 4.71 & 6.37 \\
\hline
\end{tabular}


Table 6 Initial BRB provided by examining the off-line multi-region database and operating experiences

\begin{tabular}{|c|c|c|c|c|c|c|c|}
\hline \multirow{2}{*}{$\begin{array}{l}\text { Rule } \\
\text { No. }\end{array}$} & \multirow{2}{*}{$\begin{array}{c}\text { Rule } \\
\text { Weight }\end{array}$} & \multirow{2}{*}{$Q_{e}$} & \multicolumn{5}{|c|}{$\beta$} \\
\hline & & & $D_{l}$ & $D_{2}$ & $D_{3}$ & $D_{4}$ & $D_{5}$ \\
\hline 1 & 0.9 & $R_{1}$ & 0.7 & 0.3 & 0 & 0 & 0 \\
\hline 2 & 1 & $R_{2}$ & 0.1 & 0.9 & 0 & 0 & 0 \\
\hline 3 & 1 & $R_{3}$ & 0 & 0 & 0.7 & 0.3 & 0 \\
\hline 4 & 1 & $R_{4}$ & 0 & 0 & 0 & 0.8 & 0.2 \\
\hline 5 & 0.9 & $R_{5}$ & 0 & 0 & 0 & 0.3 & 0.7 \\
\hline
\end{tabular}

Table 6 shows initial BRB provided by examining the initial off-line multi-region database and operating experiences. Then, the parameter optimization algorithm is introduced to train the BRB shown in Table 7.

Table 7 Trained BRB

\begin{tabular}{cccccccc}
\hline \multirow{2}{*}{$\begin{array}{c}\text { Rule } \\
\text { No. }\end{array}$} & Rule & Weight & $Q_{e}$ & \multicolumn{7}{c}{$\beta$} \\
\cline { 4 - 8 } & & $D_{1}$ & $D_{2}$ & $D_{3}$ & $D_{4}$ & $D_{5}$ \\
\hline 1 & 0.869 & $R_{1}$ & 0.670 & 0.265 & 0 & 0.650 & 0 \\
2 & 0.969 & $R_{2}$ & 0.066 & 0.869 & 0 & 0.065 & 0 \\
3 & 1 & $R_{3}$ & 0 & 0 & 0.655 & 0.345 & 0 \\
4 & 1 & $R_{4}$ & 0 & 0 & 0 & 0.844 & 0.156 \\
5 & 0.9 & $R_{5}$ & 0 & 0 & 0 & 0.346 & 0.654 \\
\hline
\end{tabular}

Curves in Fig. 11 exhibit an integral optimizing process. At initial time, the fired heater reaches new steady state, while oxygen concentration is loose with low thermal efficiency. At $9^{\text {th }}$ minute, the first step is the estimated optimal point calculated by RIMER. At the moment, in Fig. 11(e), the blower reduce the air flow as shown with red solid line and the induced draft fan, blue dashed line, also decreases accordingly for holding the pressure. Then the feedback control of oxygen concentration and pressure hibernates respectively for the steady state control period $n T / m T$, as covering the adjusted transient time of air flow. But the feedforward control doesn't hibernate. So while the fuel fluctuates in this time, the 
flue gas - air system response immediately. At $19^{\text {th }}$ minute, a perturbation runs, the $\bar{\eta}_{s s}$ increases from $91.11 \%$ to $91.24 \%$, then by $(10,11)$, the optimizing step $\Delta X=a_{1} g_{1}=0.310$, which runs at $29^{\text {th }}$ minute, then $\bar{\eta}_{s s}$ increases to $91.52 \%$. At $39^{\text {th }}$ minute, the next optimization begins, and $\bar{\eta}_{s s}$ from $91.52 \%$ to 91.57\%. The gap is less than $\sigma=0.10 \%$, which meets the optimization termination criterion. Then, the final step runs at $49^{\text {th }}$ minute, and the $\bar{\eta}_{s s}$ is improved about $0.8 \%$ in all.
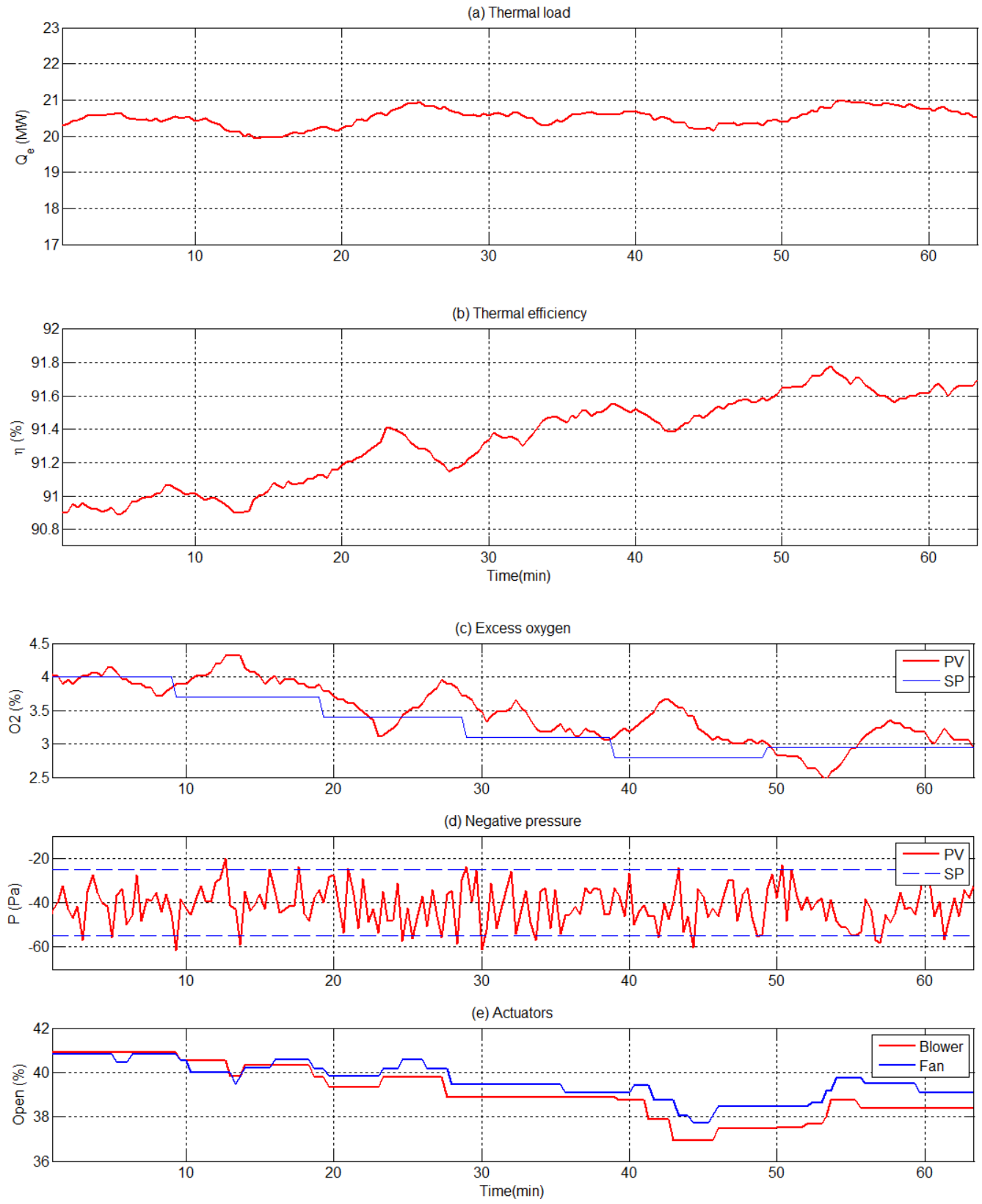

Fig. 11. Optimization performance of a fired heater in a real refinery: (a) thermal load, (b) thermal efficiency, (c) excess oxygen, (d) negative pressure, (e) actuators. 
The proposed method has attained long-term field application and guaranteed the high efficient operation. What should be highlighted is that the long-term operation and reliable thermal efficiency optimization is the main advantage of the proposed strategy.

\section{Conclusions}

A belief rule-based optimization for thermal efficiency of fired heaters combing RIMER approach and SA on-line self-optimization is proposed. Firstly, a belief-rule-base (BRB) expert system is constructed that determines the optimal steady state operation (i.e. a set of good initial values of operating parameters for a specified heat load) to quickly track the changes in thermal load. Then, once it is switched to the determined optimal steady state, SA is activated to carry out on-line selfoptimization, starting with the historical relatively optimal initial value provided by the off-line multiregional intelligent optimization $\mathrm{BRB}$ or last updated optimal initial value. And BRB is adjusted by the gap of initial value and optimal result. The online self-optimization and offline BRB updating overcome the problem from the changes of process performance, especially oxygen instrument drift. Finally, all the optimized control implemented through a practical control strategy for the flue gas - air system, which is applied to the chamber oxygen and pressure control on the basis of a flue gas-air control system. Both Simulation results on the UniSim ${ }^{\mathrm{TM}}$ Design platform and the field implementation results at a real oil refinery demonstrate the effectiveness of this optimization scheme. Moreover, the proposed method has attained long-term field application and guaranteed the high efficient operation of fired heaters.

\section{Acknowledgements}

This research was supported by the National High-Tech (863) Program of China (2013AA 040702), National Natural Science Foundation of China (No. 61673236) and the seventh framework programme of the European Union (grant number P7-PEOPLE-2013-IRSES-612230). The authors also thank the 
Santander Universities and the Tsinghua Global Scholars Fellowship Program for supporting the exchange visits between Tsinghua University and University of Surrey.

\section{Appendix}

A. Mechanic model for both dynamic and steady state

According to material balance rule, the flowing formulas works,

$$
\begin{gathered}
C_{1} \frac{d O_{2}}{d t}=21 q_{V a}-21 \lambda q_{V f}-q_{V f g} O_{2} \\
C_{2} \frac{d p}{d t}=q_{V a}+q_{V f}-q_{V f g} \\
q_{V a}=f_{1}\left(u_{1}, p\right) \\
q_{V f g}=f_{2}\left(u_{2}, p\right)
\end{gathered}
$$

where, $\mathrm{O}_{2}$ is the oxygen volume fraction of flue gas, $\% ; \mathrm{p}$ is the chamber negative pressure, Pa; $q_{V a}$ is the volume flow rate of the air; $q_{V f}$ is the fuel gas volume flow rate; $q_{V f g}$ is the volume flow rate of the flue gas; $\mathrm{C}_{1}$ and $\mathrm{C}_{2}$ are the capacity factors of oxygen volume fraction in chamber and chamber negative pressure respectively; $f_{1}$ and $f_{2}$ are the functions in terms of manipulated variables for air and flue gas respectively.

Assume that the composition of fuel gas is constant, the theoretical ratio between fuel gas and air $\lambda$ is,

$$
\lambda=0.01 \times 4.76 \times\left[0.5 \mathrm{CO}+0.5 \mathrm{H}_{2}+\sum_{m, n}\left(m+\frac{n}{4}\right) \mathrm{C}_{m} \mathrm{H}_{n}+1.5 \mathrm{H}_{2} \mathrm{~S}-\mathrm{O}_{2}\right]
$$

where, $\mathrm{CO}, \mathrm{H}_{2}, \mathrm{C}_{m} \mathrm{H}_{n}, \mathrm{H}_{2} \mathrm{~S}, \mathrm{O}_{2}$ are the volume fractions of the fuel gas components, $\%$.

For steady state case, the Eqs. (A.1) and (A.2) are degraded into,

$$
\begin{gathered}
21 q_{V a}=21 \lambda q_{V f}+q_{V f g} O_{2} \\
q_{V f g}=q_{V a}+q_{V f}
\end{gathered}
$$


Now, Eqs. (A.6) and (A.7) together with the Eqs. (A.3) and (A.4) constitutes the steady-state model of gas-air system. Moreover, Eqs. (A.3) and (A.4) preserve high nonlinearity and their formulas differ with the different actuators.

As depicted in Fig. 5, the base monitoring (control) period is $T P$, and the transition time for oxygen concentration stabilization after control actions is $\mathrm{nTP}$. So, $\mathrm{n}$ is the number of base monitoring periods for oxygen concentration stabilization.

Suppose the process is at steady state at $k$ time point, the following formula can be easily obtained based on Eqs. (A.6) and (A.7),

$$
21 q_{V a}(k)=21 q_{V f}(k) \lambda+\left[q_{V a}(k)+q_{V f}(k)\right] O_{2(k)}
$$

Then, at $k+n$ time point, the oxygen volume fraction will reach the desired set point, that is,

$$
21 q_{\text {Vass }}(k+n)=21 q_{V f}(k+n) \lambda+\left[q_{\text {Vass }}(k+n)+q_{V f}(k+n)\right] O_{2 s p}
$$

Hence, the movement of the air should be,

$$
\Delta q_{\text {Vass }}(k+n)=q_{\text {Vass }}(k+n)-q_{V a}(k)=\frac{O_{2 s p}-O_{2(k)}}{21-O_{2 s p}}\left[q_{V a}(k)+q_{V f}(k)\right]
$$

where, $\Delta q_{\text {Vass }}(k+n)$ is the desired air change to reach the oxygen concentration set-point at $\mathrm{k}+\mathrm{n}$ time point, $q_{\text {Vass }}(k+n)$ is the calculated air flowrate for $\mathrm{k}+\mathrm{n}$ time point.

Clearly, Eq. (A.10) is the control law for steady state feedback control. Moreover, it has strong physical meanings, and the air change amount is calculated from the oxygen concentration change.

The fuel gas flowrate changes is determined by the temperature control system, which is not explained in details here. For gas-air control system, the fuel gas flowrate change is a disturbance source. So, the fuel gas flowrate change is then introduced as feedforward signal to guide the air flowrate control. The air flowrate feedforward control law can be formulated as follows.

When the following condition satisfies, 


$$
\frac{\Delta q_{V f}(k)}{q_{V f 0}}>\zeta
$$

where, $q_{V f 0}$ is the fuel gas flowrate when the previous air flowrate adjustment, and $\Delta q_{V f}(k)=q_{V f}(k)-q_{V f 0}$ denotes the $\mathrm{k}$ time fuel gas flowrate change comparing with the previous air flowrate adjustment, $\zeta$ is a threshold factor.

$$
\left.\begin{array}{c}
\Delta q_{V a f f}(k+1)=\xi \lambda \Delta q_{V f}(k) \\
q_{V f 0}=q_{V f}(k)
\end{array}\right\}
$$

where, $\Delta q_{\text {Vaff }}(k+1)$ is the air flowrate feedforward change amount in case of fuel gas flowrate change.

Then, at $\mathrm{k}+1$ time, the air flowrate change should be,

$$
\Delta q_{V a}(k+1)=\Delta q_{\text {Vass }}(k+n)+\Delta q_{\text {Vaff }}(k+1)
$$

B. Convergence theorem and its proof

Taking the nonlinearity in actuator and modelling error into consideration, firstly define,

$$
\begin{gathered}
\Delta \bar{q}_{\text {Vass }}(k+n)=K(k+n) \Delta q_{\text {Vass }}(k+n) \\
\bar{q}_{\text {Vass }}(k+n)=\bar{q}_{\text {Va }}(k)+\Delta \bar{q}_{\text {Vass }}(k+n)
\end{gathered}
$$

Where, $\Delta \bar{q}_{\text {Vass }}(k+n)$ is the actual air flowrate movement at time $\mathrm{k}+\mathrm{n}, K(k+n)$ is the factor between actual flowrate movement and calculated air flowrate movement at time $\mathrm{k}+\mathrm{n}, \bar{q}_{V a}(k)$ and $\bar{q}_{\text {Vass }}(k+n)$ are actual air flowrates at time $\mathrm{k}$ and $\mathrm{k}+\mathrm{n}$ respectively.

\section{Convergence Theorem}

The sufficient condition for convergence of the proposed oxygen concentration steady-state feedback control is to satisfy,

$$
0<\frac{K(k+n)}{K_{a}(k+n)}<2
$$


where, $K_{a}(k+n)=\frac{q_{\text {Vass }}(k+n)+q_{V f}(k)}{\bar{q}_{\text {Vass }}(k+n)+q_{V f}(k)}$.

\section{Proof}

The control law proposed in Appendix A works on the real process, then at time k+n, we have,

$$
21 \bar{q}_{\text {Vass }}(k+n)=21 \bar{q}_{V f}(k) \lambda+\left[\bar{q}_{\text {Vass }}(k+n)+q_{V f}(k)\right] O_{2(k+n)}
$$

Then, the oxygen volume fraction at $\mathrm{k}+\mathrm{n}$ time point is,

$$
O_{2(k+n)}=\frac{21 \bar{q}_{\text {Vass }}(k+n)-21 q_{V f}(k) \bar{\lambda}}{\bar{q}_{\text {Vass }}(k+n)+q_{V f}(k)}
$$

Hence, the difference between oxygen set-point and the real oxygen at $\mathrm{k}+\mathrm{n}$ time point is,

$$
O_{2 s p}-O_{2(k+n)}=O_{2 s p}-\frac{21 \bar{q}_{\text {Vass }}(k+n)-21 q_{V f}(k) \bar{\lambda}}{\bar{q}_{\text {Vass }}(k+n)+q_{V f}(k)}=\frac{\left(O_{2 s p}-21\right) \bar{q}_{\text {Vass }}(k+n)+O_{2 s p} q_{V f}(k)-21 q_{V f}(k) \bar{\lambda}}{\bar{q}_{\text {Vass }}(k+n)+q_{V f}(k)}
$$

Moreover,

$$
21 q_{V f}(k) \bar{\lambda}=21 \bar{q}_{V a}(k)-\left[\bar{q}_{V a}(k)+q_{V f}(k)\right] O_{2(k)}
$$

Based on the Eqs. (A.10), (A.14), (A.15) and (A.20), Eq. (A.19) can be re-written as,

$$
\frac{O_{2 s p}-O_{2(k+n)}}{O_{2 s p}-O_{2(k)}}=1-\frac{K(k+n)}{K_{a}(k+n)}
$$

So, if $0<\frac{K(k+n)}{K_{a}(k+n)}<2$ satisfies, then,

$$
\left|\frac{O_{2 s p}-O_{2(k+n)}}{O_{2 s p}-O_{2(k)}}\right|=\left|1-\frac{K(k+n)}{K_{a}(k+n)}\right|<1
$$

The convergence is then proven.

\section{References}

[1] H. Ghosh, Improve your fired heaters, Chemical Engineering (New York), 99 (3) (1992) 116-123.

[2] Z. Jegla, J. Kohoutek, P. Stehlik, Global algorithm for systematic retrofit of tubular process furnaces, Applied Thermal Engineering, 23 (14) (2003) 1797-1805. 
[3] A. Garg, Optimize fired heater operations to save money, Hydrocarbon Processing, 76 (6) (1997) 97-104.

[4] A. Garg, Revamp fired heaters to increase capacity, Hydrocarbon Processing, 77 (6) (1998) 67-80.

[5] Z. Jegla, P. Stehlı k, J. Kohoutek, Plant energy saving through efficient retrofit of furnaces, Applied Thermal Engineering, 20 (15-16) (2000) 1545-1560.

[6] S. Mussati, J.I. Manassaldi, S.J. Benz, N.J. Scenna, Mixed Integer Nonlinear Programming model for the optimal design of fired heaters, Applied Thermal Engineering, 29 (11 - 12) (2009) 2194-2204.

[7] S. Shieh, Y. Chang, S. Jang, M. Ma, T. Huang, Statistical key variable analysis and model-based control for the improvement of thermal efficiency of a multi-fuel boiler, Fuel, 89 (5) (2010) 1141-1149.

[8] R. Zhang, S. Wang, Support vector machine based predictive functional control design for ouitput temperature of coking furnace, Journal of Process Control, 18(5) (2008) 439-448.

[9] R. Zhang, P. Li, A. Xue, A. Jiang, S. Wang, A simplified linear iterative predictive functional control approach for chamber pressure of industrial coke furnace, Journal of Process Control, 20(4) (2010) 464-471.

[10] V. Kouprianov, C. Chullabodhi, W. Kaewboonsong, Cost based optimization of excess air for fuel oil/gasfired steam boilers, RERIC International Energy Journal, 21 (2) (1999) 83-91.

[11] V.I. Kouprianov, V. Tanetsakunvatana, Optimization of excess air for the improvement of environmental performance of a $150 \mathrm{MW}$ boiler fired with Thai lignite, Applied Energy, 74 (3 - 4) (2003) 445-453.

[12] V.I. Kouprianov, Applications of a cost-based method of excess air optimization for the improvement of thermal efficiency and environmental performance of steam boilers, Renewable and Sustainable Energy Reviews, 9 (5) (2005) 474-498.

[13] V. Tanetsakunvatana, V.I. Kuprianov, Experimental study on effects of operating conditions and fuel quality on thermal efficiency and emission performance of a 300-MW boiler unit firing Thai lignite, Fuel Processing Technology, 88 (2) (2007) 199-206.

[14]R.J. Zhang, J. Lu, G.Q. Zhang, A knowledge-based multi-role decision support system for ore blending cost optimization of blast furnaces, European Journal of Operational Research, 215 (1) (2011) 194-203.

[15] W.X. Lv, X.Y. Gao, D.X. Huang, Y.H. Jin, J. Yi, J. Wang, Research on intelligent optimal control of thermal efficiency of furnace (in Chinese), Chinese Journal of Scientific Instrument, 30 (6) (2009) 108-113.

[16] J.B. Yang, J. Liu, J. Wang, H.S. Sii, H.W. Wang, Belief rule-base inference methodology using the evidential reasoning Approach-RIMER, Systems, Man and Cybernetics, Part A: Systems and Humans, IEEE Trans. on, 36 (2) (2006) 266-285.

[17] S. Patel, Simplify your thermal efficiency calculation: Standard charts and a spreadsheet help, Hydrocarbon Processing, 84 (7) (2005) 63--69.

[18] S.J. Liang, Z.Y. Wu, X.D. Wang, SY/T 6381-2008 Heat determination for heating furnace (in Chinese), Beijing: China Petroleum Press, 2008.

[19]H. Ibrahim, M. Al-Qassimi, Matlab program computes thermal efficiency of fired heater, Periodica Polytechnica Chemical Engineering, 52 (2) (2008) 61-69.

[20] A.M. Bagirov, J. Ugon, D. Webb, Fast modified global k-means algorithm for incremental cluster construction, PATTERN RECOGNITION, 44 (4) (2011) 866-876.

[21] Y. Li, W. Zhang, D. Huang, G. Xu, J. Wang, J. Zhou, Thermal efficiency optimization of heating furnace using historical data and AHH model (in Chinese), Journal of Nanjing University of Science and Technology, 35 (SUPPL.1) (2011) 32-37.

[22] J. Liu, J.B. Yang, J. Wang, H.S. Sii, Engineering system safety analysis and synthesis using the fuzzy rulebased evidential reasoning approach, Quality and Reliability Engineering International, 21 (4) (2005) 387411.

[23]D.L. Xu, J. Liu, J.B. Yang, G.P. Liu, J. Wang, I. Jenkinson, J. Ren, Inference and learning methodology of belief-rule-based expert system for pipeline leak detection, Expert Systems with Applications, 32 (1) (2007) 
103-113.

[24]Z.J. Zhou, C.H. Hu, J.B. Yang, D.L. Xu, D.H. Zhou, Online updating belief rule based system for pipeline leak detection under expert intervention, Expert Systems with Applications, 36 (4) (2009) 7700-7709.

[25]Z.J. Zhou, C.H. Hu, J.B. Yang, D.L. Xu, D.H. Zhou, Online Updating Belief-Rule-Base Using the RIMER Approach, Systems, Man and Cybernetics, Part A: Systems and Humans, IEEE Transactions on, 41 (6) (2011) 1225-1243.

[26] G.L. Kong, D.L. Xu, X.B. Liu, J.B. Yang, Applying a belief rule-base inference methodology to a guidelinebased clinical decision support system, Expert Systems, 26 (5) (2009) 391-408.

[27]L. Dymova, P. Sevastianov, P. Bartosiewicz, A new approach to the rule-base evidential reasoning: Stock trading expert system application, Expert Systems with Applications, 37 (8) (2010) 5564-5576.

[28]X.D. Yu, D.X. Huang, Y.H. Jiang, Y.H. Jin, Iterative learning belief rule-base inference methodology using evidential reasoning for delayed coking unit, Control Engineering Practice, 20 (10) (2012) 1005-1015.

[29]X.S. Si, C.H. Hu, J.B. Yang, Z.J. Zhou, A New Prediction Model Based on Belief Rule Base for System's Behavior Prediction, IEEE Transactions on Fuzzy Systems, 19 (4) (2011) 636-651.

[30] J.B. Yang, J. Liu, D.L. Xu, J. Wang, H.W. Wang, Optimization Models for Training Belief-Rule-Based Systems, Systems, Man and Cybernetics, Part A: Systems and Humans, IEEE Transactions on, 37 (4) (2007) 569-585.

[31] Y. Wang, J. Yang, D. Xu, Environmental impact assessment using the evidential reasoning approach, European Journal of Operational Research, 174 (3) (2006) 1885--1913.

[32] J.C. Spall, Implementation of the simultaneous perturbation algorithm for stochastic optimization, IEEE Transactions on Aerospace and Electronic Systems, 34 (3) (1998) 817-823.

[33]W.Y. Zhang, Y. Li, D.X. Huang, J. Yi, Z Zhang, X Yang, Control of flue gas-air system for fired heaters based on steady state model (in Chinese), Journal of Zhejiang University, 45 (12) (2011) 2093-2098.

[34]H.S. Zeng, Z.P. Zheng, Z.Z Liu, D.M. Zhang, C.J. Ding. Application of analyzer for flue gas on raising combustion efficiency (in Chinese). China National Energy and Chemical Industry Annual Conference, 2006.

[35]L.G. Qi, X.Y. Gao, D.X. Huang, L. Wang, H.J. Wang, S.G. Song. A novel comprehensive solution for furnace integrating outlet parametric variable control and online thermal efficiency optimization. Chinese Control Conference, 2015, Hangzhou, China.

[36] W.Y. Zhang, D.X. Huang, Y.D. Wang, J.C. Wang. Adaptive state feedback predictive control and expert control for a delayed coking furnace. Chinese Journal of Chemical Engineering, 2008, 16(4): 590-598. 